\title{
Implementasi Promosi Kesehatan untuk Menurunkan Kasus Stunting di Wilayah Kerja Puskesmas Darajuanti Kabupaten Sintang
}

\author{
Ria Risti Komala Dewi ${ }^{1)}$ dan Gandha Sunaryo Putra ${ }^{2)}$ \\ ${ }^{12)}$ Universitas Muhammadiyah, Pontianak, Indonesia \\ Corresponding Author: Gandha S. Putra, gandhasunaryoputra90@gmail.com
}

\begin{abstract}
Abstrak: Puskesmas Dara Juanti menduduki peringkat pertama dengan kasus stunting tertinggi di Kecamatan Sintang dengan angka kejadian sebesar 26,62 \% pada Tahun 2016, mengalami peningkatan sebesar 27,02\% pada tahun 2017, dan pada tahun 2018 turun menjadi 22,79\%. Walaupun kasus stunting mengalami penurunan, akan tetapi kasus stunting maksimal yang dipersyaratkan oleh World Health Organization (WHO) adalah 20\%. Permasalahan yang terjadi di wilayah kerja Puskesmas Darajuanti yaitu belum dilakukannya program intervensi yang efektif terhadap kasus stunting khususnya peningkatan pemahaman akan pentingnya asupan gizi dan cara pengasuhan yang benar pada ibu yang memiliki balita. Adapun solusi yang akan dilaksanakan dalam rangka penyelesaian masalah diatas adalah peningkatan pengetahuan melalui penyuluhan tentang gizi balita dan praktik pemberian makan pada balita di Wilayah Kerja Puskesmas Darajuanti. Tujuan dan target khusus yang ingin dicapai dari kegiatan ini adalah meningkatkan pengetahuan ibu balita tentang pentingnya asupan gizi dan cara pengasuhan yang benar pada balitanya serta peningkatan pengetahuan tentang bahaya stunting. Kegiatan dilaksanakan pada tanggal 12 September 2020 di posyandu Ulak Jaya. Metode pelaksanaan yang digunakan dalam pengabdian ini adalah sosialisasi, penyuluhan, dan pelatihan. Hasil kegiatan juga menunjukkan bahwa terdapat perbedaan yang bermakna tingkat pengetahuan responden sebelum dan sesudah dilaksanakan penyuluhan ( $p$ value $=0,00$ ).
\end{abstract}

Kata Kunci: promosi kesehatan, balita, stunting, Puskesmas Dara Juanti

\begin{abstract}
Puskesmas Dara Juanti was ranked first with the highest stunting cases in Sintang District with an incidence rate of $26.62 \%$ in 2016, an increase of $27.02 \%$ in 2017, and 2018 it decreased to 22.79\%. Although stunting cases have fallen, the World Health Organization (WHO) 's maximum standard for stunting is 20\%. The problem that occurs in the Darajuanti Health Center's working area is that there has not been an effective intervention program for stunting cases, significantly an increase in understanding of the importance of nutritional intake and proper care methods for mothers with children under five. The solution that will be implemented to solve the above problem is increasing knowledge through counseling on toddler nutrition and feeding practices for toddlers in the Darajuanti Health Center Work Area. The specific goals and targets to be achieved from this activity are to increase the knowledge of mothers under five about the importance of nutritional intake and proper care for their children and increase understanding about the dangers of stunting. The activity was held on September 12, 2020, at the Ulak Jaya posyandu. The implementation method used in this service is socialization, counseling, and training. The activity results also indicated a significant difference in the respondents' level of knowledge before and after the counseling was carried out ( $p$-value $=0.00$ ).
\end{abstract}

Keywords: Health promotion, balita, stunting, Puskesmas Dara Juanti 


\section{Pendahuluan}

Masalah stunting (anak pendek) merupakan salah satu permasalahan gizi yang mempengaruhi potensi pertumbuhan anak-anak diseluruh dunia (Tariku, 2017). Stunting adalah istilah yang menggambarkan tentang status gizi seseorang berdasarkan penilaian tinggi badan menurut umur (Latif dan Istiqomah, 2017). Estimasi Insiden stunting secara global pada tahun 2018 adalah sebesar 21,9\% atau 149 juta anak-anak di bawah 5 tahun di dunia mengalami stunting. Di Asia Tenggara sebesar 25\% atau sekitar 37,3 juta anak diperkirakan mengalami stunting (UNICEF, 2019).

Prevalensi balita pendek menjadi masalah kesehatan masyarakat jika prevalensinya $20 \%$ atau lebih. Indonesia merupakan negara yang mempunyai prevalensi balita pendek tertinggi di bandingkan dengan negara-negara tetangga. Jumlah kasus balita pendek di negara Myanmar sebesar 35\%, Vietnam 23\%, Malaysia 17\%, Thailand 16\%, Singapura 4\% dan di negara Indonesia status balita pendek tercatat 7,8 juta dari 23 juta balita adalah penderita stunting sekitar 35,6\%. Dari jumlah tersebut sebanyak 18,5\% kategori sangat pendek dan 17,1\% kategori pendek (Kemenkes RI, 2017a).

Stunting merupakan salah satu permasalahan kesehatan di Kalimantan Barat. Berdasarkan hasil pemantuan status gizi yang dilaksanakan secara nasional pada tahun 2015 tercatat jumlah kasus stunting 12\%, meningkat menjadi 34,9\%, pada Tahun 2016 dan meningkat kembali menjadi 36,5\% pada Tahun 2017 (Kemenkes RI, 2017b). Kabupaten Sintang merupakan salah satu kabupaten di Provinsi Kalimantan Barat yang termasuk wilayah 3T (tertinggal, terdepan dan terluar) dan memiliki kasus stunting yang cukup besar. Berdasarkan hasil Pemantauan Status Gizi Tahun 2016 Kabupaten Sintang memiliki prevalensi stunting sebesar 34\% dan meningkat sebesar 10,1\% pada Tahun 2017 menjadi sebesar $44,1 \%$ (Dinkes Sintang, 2017).

Pemantauan status gizi juga dilakukan di Kabupaten Sintang secara serempak yang dilaksanakan pada bulan Juli, Agustus, dan September di seluruh Puskesmas di wilayah Kabupaten Sintang. Dari hasil Pemantauan Status Gizi didapatkan bahwa Puskesmas Dara Juanti menduduki peringkat pertama di Kecamatan Sintang dengan angka kejadian stunting diatas 20\%. Pada tahun 2016 prevalensi kasus stunting di Puskesmas Dara Juanti sebesar 26,62\%. Kemudian kasus stunting mengalami peningkatan sebesar 27,02\% pada tahun 2017 (Dinkes Sintang, 2017). Pada tahun 2018 kasus stunting turun menjadi 22,79\% (Dinkes Sintang, 2018). Walaupun kasus stunting mengalami penurunan, akan tetapi kasus stunting maksimal yang dipersyaratkan oleh World Health Organization (WHO) adalah $20 \%$.

Banyak faktor yang mempengaruhi kejadian stunting. Diantaranya penelitian yang dilakukan oleh Ni'mah,dkk pada Tahun 2015 yang menyatakan bahwa pengetahuan gizi ibu yang kurang sangat berhubungan terhadap kejadian stunting pada balita $(\mathrm{p}=0,015)$. Selain itu, penelitian yang dilakukan oleh Hapsari, dkk. (2019) di wilayah kerja Puskesmas Darajuanti menunjukkan terdapat hubungan antara pola asuh dan personal hygiene dengan kejadian stunting ( $\mathrm{p}$ value $<0,05)$.

Pentingnya masalah stunting di wilayah $3 \mathrm{~T}$ ini untuk ditangani karena stunting dapat menghambat perkembangan anak, dengan dampak negatif yang akan berlangsung dalam kehidupan selanjutnya seperti penurunan intelektual, rentan terhadap penyakit tidak menular, penurunan produktivitas hingga menyebabkan kemiskinan dan risiko melahirkan bayi dengan berat lahir rendah. Hal ini dapat berdampak pada penurunan kualitas Sumber Daya Manusia (SDM) di wilayah 3T. Masyarakat setempat sangat berharap adanya program intervensi yang efektif terhadap kasus stunting karena selama ini belum ada program intervensi yang efektif yang dilakukan yang dapat menurunkan kasus stunting, khususnya pemahaman akan pentingnya asupan gizi, personal hygiene dan cara engasuhan yang benar pada balita mereka. 


\section{Metodologi}

Metode yang digunakan dalam melaksanakan kegiatan ini adalah dengan melakukan sosialisasi, penyuluhan, dan pelatihan. Ketiga metode ini dilakukan agar hasil yang diharapkan dalam kegiatan ini bisa tercapai serta untuk saling melengkapi kekurangan dari masing-masing metode yang ada. Kegiatan ini dilaksanakan di Kelurahan Ulak Jaya Kabupaten Sintang. Waktu pelaksanaan kegiatan ini dilaksanakan pada Bulan September 2019. Adapun tahapan kegiatan pengabdian disajikan pada Gambar 1.

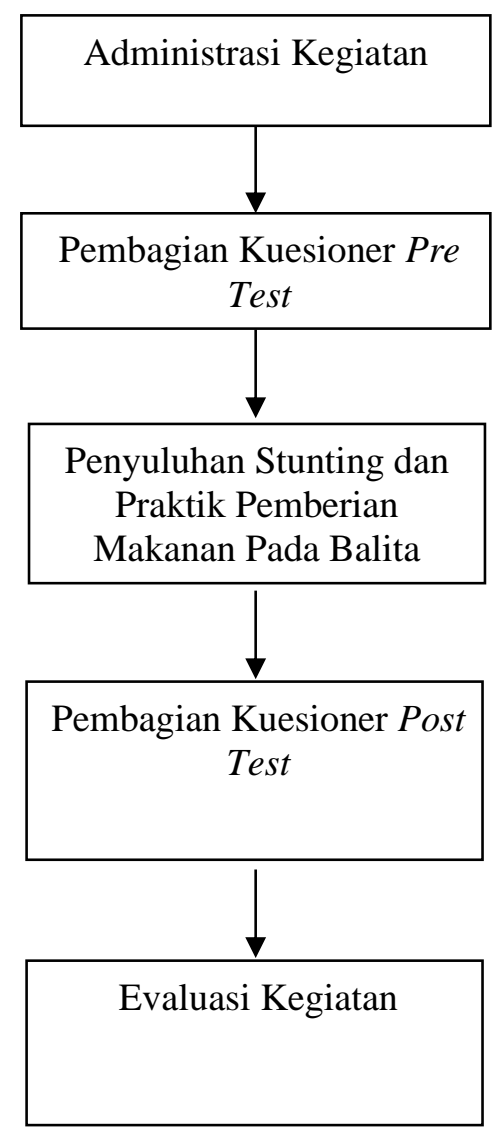

Gambar 1. Alur Pelaksanaan Kegiatan Pengabdian Masyarakat

\section{Hasil dan Pembahasan}

\section{A. Promosi Kesehatan tentang Stunting dan Praktik Pemberian Makan}

Promosi kesehatan tentang stunting dan praktik pemberian makan dilakukan di posyandu Kelurahan Ulak Jaya. Pelaksanaan kegiatan dilakukan di Kelurahan Ulak Jaya di karenakan Kelurahan Ulak Jaya merupakan Kelurahan yang angka kejadian stuntingnya cukup tinggi dan lokasinya lebih mudah dijangkau.

Kegiatan ini dilakukan untuk mengetahui tingkat pemahaman ibu-ibu mengenai status gizi anak, pengetahuan mereka tentang stunting, cara pencegahan stunting dan cara pemberian makan serta pengasuhan pada anak. Kegiatan dihadiri oleh 40 peserta perwakilan ibu-ibu dari setiap kelurahan di wilayah Puskesmas Darajuanti, kader posyandu dan 3 orang tenaga kesehatan, beserta 1 (satu) orang perwakilan dari perangkat desa. 


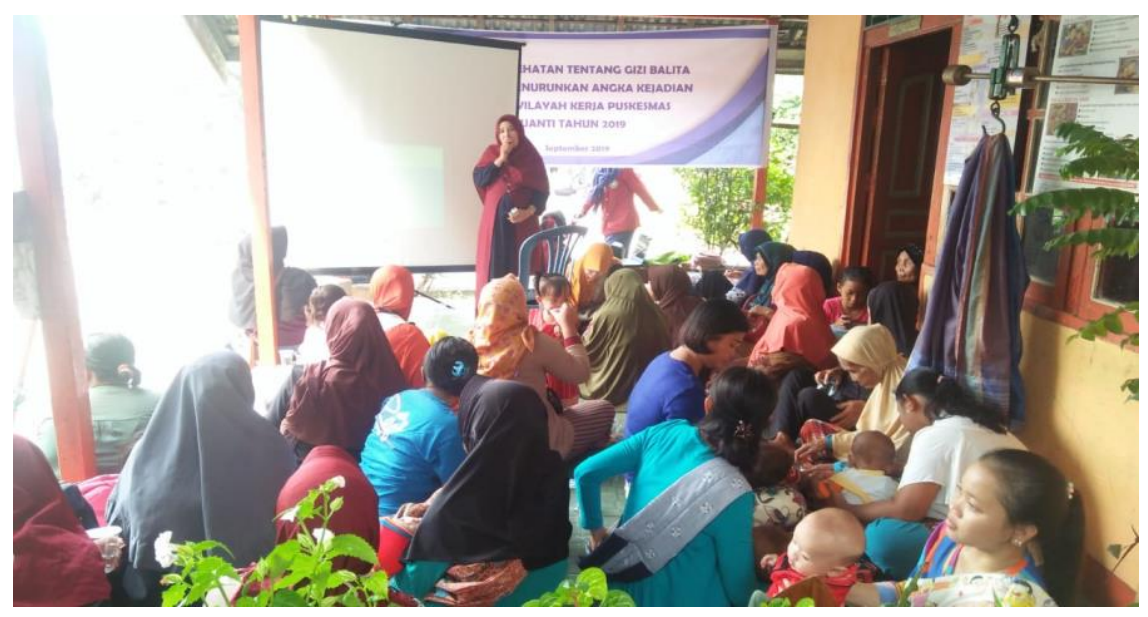

Gambar 1. Kegiatan Penyuluhan Kesehatan Mengenai Stunting

Kegiatan dimulai dengan memberikan kuisioner pre-test untuk mengetahui tingkat pemahaman dan pengetahuan ibu tentang kejadian stunting dan praktik pemberian makan sebelum diberikan penyuluhan. Setelah mengisi lembar pre-test, dilanjutkan dengan penyuluhan tentang stunting dilanjutkan dengan praktik pemberian makan. Materi yang disampaikan meliputi definisi stunting, penyebab stunting, akibat stunting, deteksi dini stunting dan gejala stunting, cara pencegahan stunting, manfaat ASI Eksklusif, manfaat imunisasi, makanan bergizi bagi ibu hamil dan cara serta teknik pemberian makan pada balita.

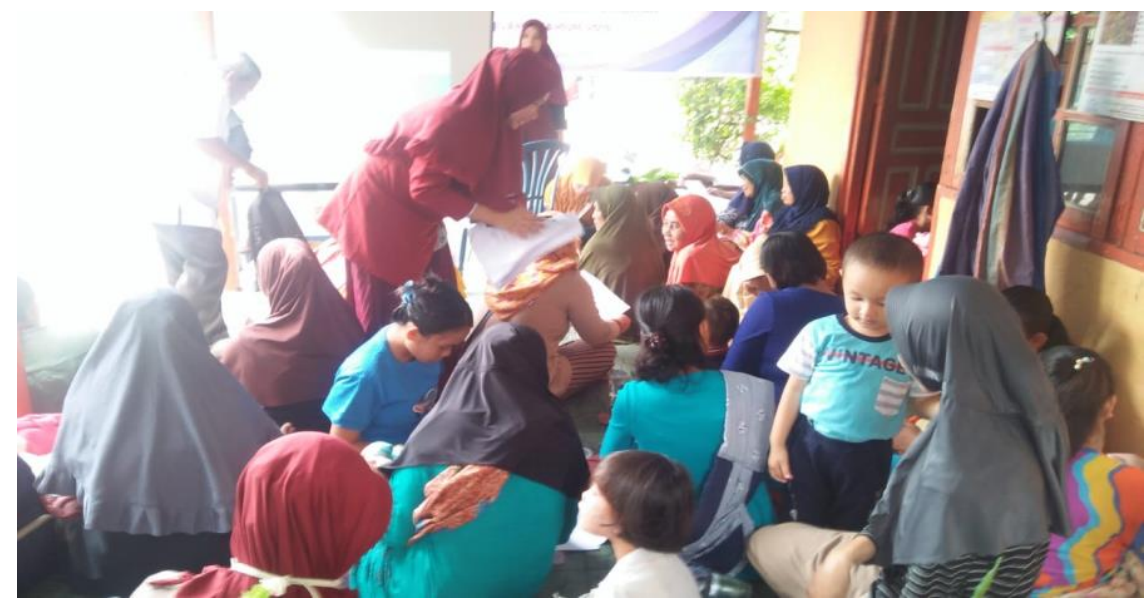

Gambar 2. Pembagian Kuesioner Pre Test Sebelum di Mulai Penyuluhan

Selanjutnya dilakukan diskusi dan Tanya jawab mengenai materi yang telah disampaikan. Kemudian ibu-ibu diberikan pertanyaan seputar yang telah disampaikan sebelumnya. Bagi yang bisa menjawab diberikan cenderamata. Ibu-ibu selanjutnya diberi kuisioner post-test untuk melihat apakah terjadi peningkatan pengetahuan tentang stunting setelah diberikan penyuluhan. Kegiatan diakhiri dengan pemberian cenderamata kepada peserta yang dapat menjawab pertanyaan, perwakilan desa dan perwakilan dari Puskesmas Darajuanti.

Untuk mengetahui tingkat keberhasilan dari pelaksanaan kegiatan, dilakukan pembagian kuesioner pre test sebelum dilakukan penyuluhan dan kuesioner post test setelah dilakukan penyuluhan. Berdasarkan analisis hasil pengolahan data menunjukkan $p$ value sebesar 0,000 yang berarti terdapat perbedaan yang bermakna tingkat pengetahuan responden sebelum dan 
sesudah dilaksanakan penyuluhan. Hasil uji statistik juga menunjukkan nilai rata-rata (mean) tingkat pengetahuan responden sebelum penyuluhan sebesar 6,60 serta nilai rata-rata setelah penyuluhan sebesar 8,68. Hal ini menunjukkan bahwa terjadi peningkatan nilai mean pengetahuan responden sebesar 2,08 setelah diberikan penyuluhan.

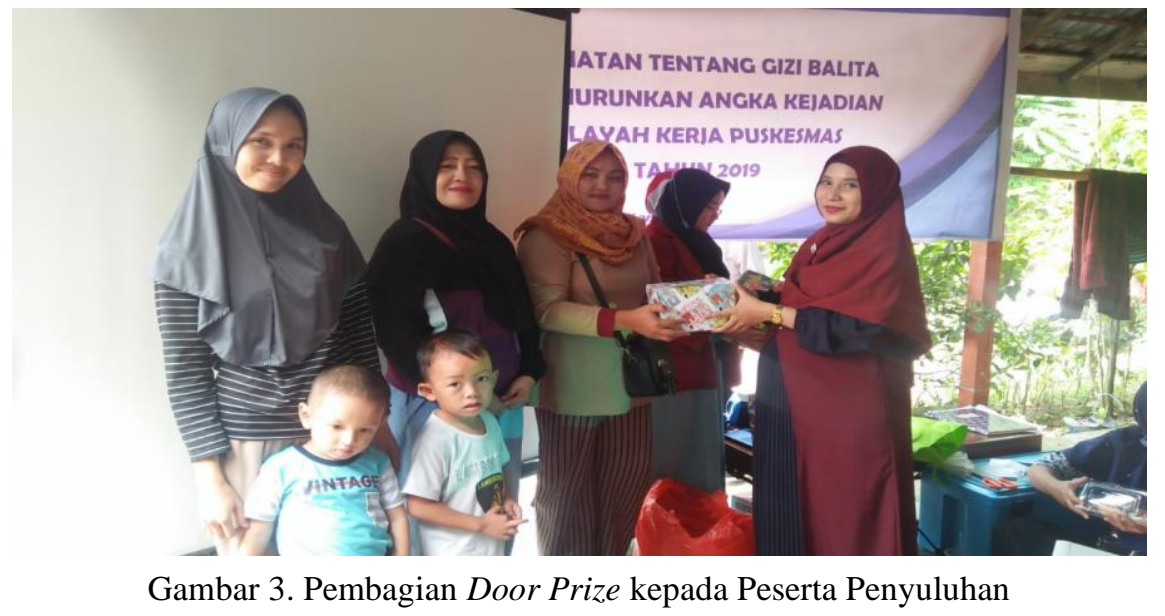

Tabel 1. Perbedaan Mean Pengetahuan Sebelum dan Sesudah dilaksanakan penyuluhan

\begin{tabular}{|l|c|c|c|}
\hline \multicolumn{2}{|c|}{ Variabel } & Mean & p value \\
\hline Pengetahuan & Sebelum & 6,60 & 0,00 \\
\cline { 2 - 3 } & Sesudah & 8,68 & \\
\hline
\end{tabular}

Dengan adanya penyuluhan diharapkan dalam kurun waktu tertentu pengetahuan masyarakat khususnya ibu-ibu yang memiliki bayi dan balita dapat meningkat disertai dengan perubahan sikap dan perilaku mereka. Diharapkan hal ini bisa membantu dalam menurunkan kasus stunting sampai $20 \%$ sesuai dengan standar dari WHO.

\section{B. Pembahasan}

Promosi Kesehatan pada hakekatnya adalah suatu kegiatan atau usaha untuk menyampaikan pesan (informasi) kesehatan kepada masyarakat, kelompok, atau individu agar memperoleh pengetahuan tentang kesehatan. Pengetahuan kesehatan yang diperoleh diharapkan dapat berpengaruh terhadap perilaku masyarakat yaitu peningkatan perilaku sehat. Perilaku sehat diartikan sebagai perilaku proaktif untuk memelihara dan meningkatkan kesehatan, mencegah resiko terjadinya penyakit, melindungi diri dari ancaman penyakit serta berperan dalam gerakan kesehatan (Triwibowo, 2015).

Berdasarkan penelitian yang dilakukan oleh Andriani, dkk. (2017) menunjukkan bahwa penyuluhan kesehatan yang dilakukan pada masyarakat di Wilayah Kerja Puskesmas Puuwatu Kota Kendari berhasil meningkatkan pengetahuan masyarakat secara signifikan. Nilai median pretest adalah 7 dan post test memiliki nilai median 13. Hasil uji statistik diperoleh hasil dengan nilai p sebesar 0,000 . Nilai p menunjukkan $<0,05$ maka Ho ditolak, sehingga dapat disimpulkan bahwa terdapat perbedaan bermakna pengetahuan sebelum dan sesudah diberikan penyuluhan kesehatan pada ibu dalam pencegahan stunting di Wilayah Kerja Puskesmas Puuwatu Kota Kendari. 
Dalam kegiatan pengabdian masyarakat ini tim pengabdian juga melibatkan para kader posyandu yang ada di masyarakat setempat. Hal ini dimaksudkan agar para kader posyandu yang terlibat dalam kegiatan penyuluhan ini dapat membantu dalam menyampaikan informasi yang diperolehnya ke masyarakat terutama para ibu-ibu yang memiliki bayi dan balita.

Kegiatan ini sejalan dengan yang dilakukan oleh Adistie, dkk. (2019) yang melakukan pemberdayaan kader kesehatan dalam deteksi dini stunting dan stimulasi tumbuh kembang balita pada masyarakat di wilayah kerja Puskesmas Jatinangor. Kegiatan dilakukan dengan memberikan ceramah, diskusi, simulasi dan praktikum. Hasil kegiatan ini menunjukkan nilai rata skor pengetahuan kader pada pre test sebesar 8,3 dan nilai post test sebesar 15,3 yang berarti terdapat peningkatan skor pengetahuan kader sebesar 7 sesudah diadakan penyuluhan. Hasil uji statistik juga menunjukkan $p$ value sebesar 0,00 yang berarti terdapat perbedaan yang bermakna skor pengetahuan kader sebelum dan sesudah diadakan penyuluhan.

Pada kegiatan ini, selain diberikan penyuluhan kesehatan, juga dilakukan praktik pemberian makanan pada balita. Hal ini karena metode penyuluhan dengan sistem ceramah juga memiliki beberapa keterbatasan seperti peserta didik menjadi pasif, sedikit mengandung daya kritis peserta didik, sulit untuk mengendalikan sejauh mana pemahaman peserta didik dan jika terlalu lama dapat membuat jenuh peserta didik (Adistie, dkk., 2019)

Oleh sebab itu dalam kegiatan ini juga dilakukan simulasi praktik pemberian makanan pada balita untuk melengkapi kelemahan dari metode penyuluhan dengan sistem ceramah. Metode demonstrasi dilakukan dengan cara memperagakan benda, kejadian, aturan, dan urutan melakukan suatu kegiatan, baik secara langsung maupun melalui penggunaan media pengajaran yang relevan dengan pokok bahasan atau materi yang disajikan. Dengan begitu diharapkan, sasaran dapat mengetahui dan memahami setiap tahapan serta cara dalam memberikan makanan pada balita (Adistie, dkk., 2019)

\section{Simpulan}

Simpulan dari program kegiatan pengabdian masyarakat ini adalah Kegiatan promosi kesehatan untuk menurunkan kasus stunting di wilayah kerja Puskesmas Darajuanti Kabupaten Sintang telah terlaksana dengan lancar. Kegiatan yang sudah dilakukan dengan memberikan penyuluhan kesehatan dan praktik pemberian makanan pada balita. Kegiatan dihadiri oleh 40 peserta perwakilan ibu-ibu dari setiap kelurahan di wilayah Puskesmas Darajuanti, kader posyandu dan 3 orang tenaga kesehatan, beserta 1 (satu) orang perwakilan dari perangkat desa. Hasil kegiatan juga menunjukkan bahwa terdapat perbedaan yang bermakna tingkat pengetahuan responden sebelum dan sesudah dilaksanakan penyuluhan $(p$ value $=0,00)$. Diharapkan kegiatan promosi kesehatan khususnya mengenai stunting ini bisa terjadwal rutin. Hal ini dilakukan dalam upaya menurunkan kasus stunting yang masih cukup tinggi di wilayah kerja Puskesmas Darajuanti. Diharapkan dengan seringnya dilaksanakan kegiatan promosi kesehatan ini, kasus stunting yang ada di wilayah kerja Puskesmas Darajuanti bisa ditekan hingga di bawah $20 \%$. Selain itu, diharapkan para masyarakat serta kader posyandu dapat berperan serta aktif dalam menerapkan pengetahuan yang sudah di dapat dalam kegiatan ini untuk diterapkan dalam kehidupan sehari-hari serta bisa membantu dalam menyampaikan informasi ini kepada masyarakat sekitar 


\section{Ucapan Terima Kasih}

Ucapan terimakasih disampaikan Kepada Universitas Muhammadiyah Pontianak Kampus Sintang, Puskesmas Dara Juanti, Kelurahan Ulak Jaya, dan Masyarakat Desa Ulak Jaya yang yang telah banyak memberikan dukungan dalam kegiatan ini.

\section{Daftar Pustaka}

Adistie, F., Lumbantobing, V.B.M, and Maryam, N.N.A., 2019. Pemberdayaan Kader Kesehatan Dalam Deteksi Dini Stunting dan Stimulasi Tumbuh Kembang pada Balita, Jurnal Universitas Padjajaran, 1(2), 2018, hal. 173-184.

Andriani, W.O.S, Rezal, F, Nurzalmariah, W.D.S.T., 2017. Perbedaan Pengetahuan, Sikap, dan Motivasi Ibu Sesudah Diberikan Program Mother Smart Grounding (MSG) dalam Pencegahan Stunting Di Wilayah Kerja Puskesmas Puuwatu Kota Kendari Tahun 2017, Jurnal Ilmiah Mahasiswa Kesehatan Masyarakat, 2(6), 2017, hal. 1-9.

Dinkes Sintang, 2017. Laporan Kegiatan Pemantauan Status Gizi tahun 2017 Kabupaten, Dinas Kesehatan Kabupaten Sintang.

Dinkes Sintang, 2018. Laporan Kegiatan Pemantauan Status Gizi tahun 2018 Kabupaten Sintang, Dinas Kesehatan Kabupaten Sintang.

Hapsari, D.I, Dewi, R.R.K., dan Selviana. 2019. Deteminan Kejadian Stunting Pada Balita di Wilayah 3T (Tertinggal, Terdepan, dan Terluar), Jurnal Publikasi Kesehatan Masyarakat Indonesia, 6(2), 2019.

Kemenkes RI, 2017a. Buku Saku Pemantauan Status Gizi 2017, Kementerian Kesehatan Republik Indonesia.

Kemenkes RI, 2017b. Profil Kesehatan Indonesia tahun 2017, Kementerian Kesehatan Republik Indonesia.

Latif, RVN dan Istiqomah, N. 2017. Determinan Stunting Pada Siswa SD Di Kabupaten Pekalongan. Unnes Journal Of Public Health. 6(1): hal. 69-74

Ni'mah Khoirun, et.al, 2015. Faktor Yang Berhubungan Dengan Kejadian Stunting Pada Balita. Jurnal Media Gizi Indonesia, 10(1), 2015.

Tariku, A. et al. 2017. Stunting and Its Determinant Factors Among Children Aged 6-59 Months in Ethiopia, Italian Journal of Pediatrics 43(112): hal. 1-9

Triwibowo, C. dan Pusphandani, M.E., 2015. Pengantar Dasar Ilmu Kesehatan Masyarakat, Penerbit Nuhs Medika.

UNICEF, 2019. Levels and Trends in Child Malnutrition 2019. World Health Organization, New York. UNICEF 